\title{
Cesarean Section Scar Nodule, Ovarian Cyst, and Dysmenorrhea
}

\author{
Manuel Gonçalves-Henriques', Pedro Brandão $0^{2,3^{*}}$, Amélia Almeida ${ }^{4}$, Paula Ramôa ${ }^{5}$ \\ 'Department of Obstetrics and Gynecology, Hospital Professor Fernando da Fonseca, Amadora, Lisbon, Portugal, ${ }^{2}$ Department of Reproductive Medicine, Instituto \\ Valenciano de Infertilidad, Valencia, Spain, ${ }^{3}$ Faculty of Medicine, University of Porto, Porto, Portugal, ${ }^{4}$ Department of Obstetrics and Gynecology, Centro Hospitalar \\ Médio Ave, Famalicão, Portugal, ${ }^{5}$ Department of Obstetrics and Gynecology, Hospital Lusíadas Porto, Porto, Portugal
}

\section{Section 1 - Quiz \\ Case description}

A 38-year-old female was admitted in the gynecology outpatient's clinic due to secondary infertility. She was Gesta I Para I, with one previous uneventful pregnancy and a cesarean section 7 years before. She had hypothyroidism and was medicated with levothyroxine $150 \mu \mathrm{g}$. As soon as she left the combined pill in order to conceive, she started complaining of severe dysmenorrhea (pain score: 8/10). At physical examination, a hard and painful nodule was palpable at midline, under the cesarean section scar. She had a nonmobile uterus. A painful hard mass was palpable at rectal digital examination, $3 \mathrm{~cm}$ away from the anus.

Abdominal wall soft tissue ultrasound revealed a nodule of heterogeneous echogenicity with $41 \mathrm{~mm} \times 34 \mathrm{~mm} \times 17 \mathrm{~mm}$ located medially at the level of the rectus abdominis muscle, under the cesarean section scar [Figures 1-3]. Abdominal

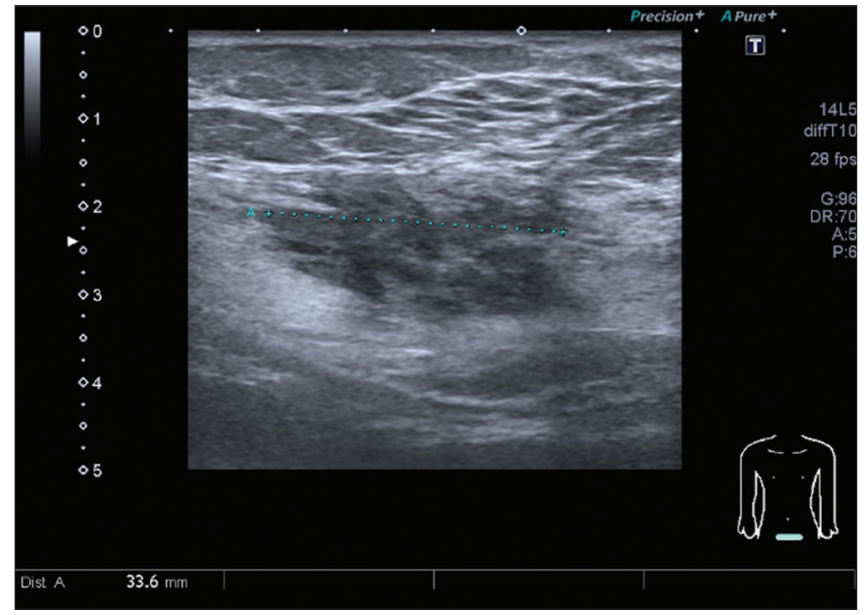

Figure 1: Abdominal soft tissue ultrasound in the axial plane revealing abdominal wall nodule

Received: 04-05-2020 Revised: 17-06-2020 Accepted: 07-08-2020 Available Online: 01-10-2020

\begin{tabular}{|l|l|}
\hline \multicolumn{3}{|c|}{ Access this article online } \\
\hline Quick Response Code: & Website: \\
& www.jmuonline.org \\
& \\
\end{tabular}

magnetic resonance imaging confirmed the presence of a nodule with $4.9 \mathrm{~cm} \times 3.8 \mathrm{~cm} \times 2.0 \mathrm{~cm}$ on the rectus abdominis muscle and its fascia [Figures 4 and 5]. Pelvic transvaginal ultrasound revealed normal uterus and right adnexa and a cyst at the left ovary with $30 \mathrm{~mm} \times 26 \mathrm{~mm}$, with no septa or solid components and with ground glass echogenicity.

The patient was submitted to laparotomy. During surgery, a hard median nodule with $5 \mathrm{~cm}$ of length was found located in the rectus abdominis muscle and its fascia [Figures 6 and 7]. Pelvic anatomy was completely distorted with several adhesions between the uterus, the adnexa, colon, and pelvic wall. The left adnexa was involved in adhesions, the left tube

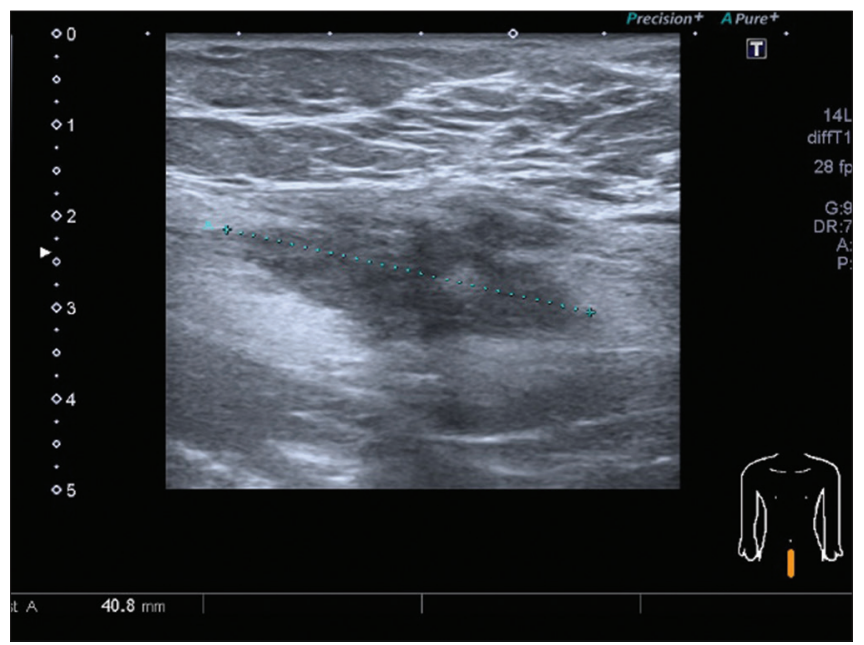

Figure 2: Abdominal soft tissue ultrasound in the sagittal plane revealing abdominal wall nodule

Address for correspondence: Dr. Pedro Brandão Department of Reproductive Medicine, Instituto Valenciano de Infertilidad, Plaza de la Policia Local 3, 46015 Valencia, Spain E-mail: pedro.brandao@ivirma.com

This is an open access journal, and articles are distributed under the terms of the Creative Commons Attribution-NonCommercial-ShareAlike 4.0 License, which allows others to remix, tweak, and build upon the work non-commercially, as long as appropriate credit is given and the new creations are licensed under the identical terms.

For reprints contact: WKHLRPMedknow_reprints@wolterskluwer.com

How to cite this article: Gonçalves-Henriques M, Brandão P, Almeida A, Ramôa P. Cesarean section scar nodule, ovarian cyst, and dysmenorrhea. J Med Ultrasound 2021;29:230-1 


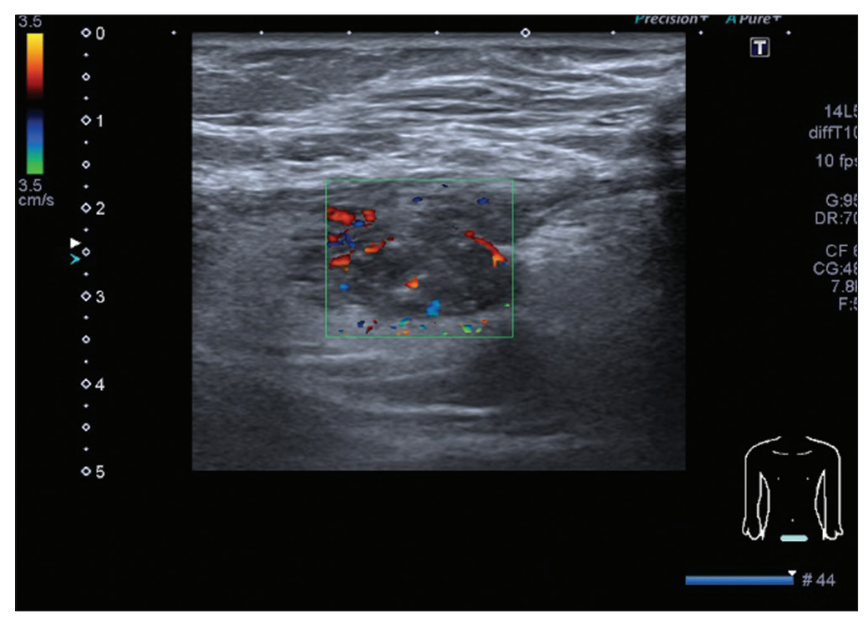

Figure 3: Abdominal soft tissue ultrasound in the axial plane with color Doppler revealing vascularized abdominal wall nodule

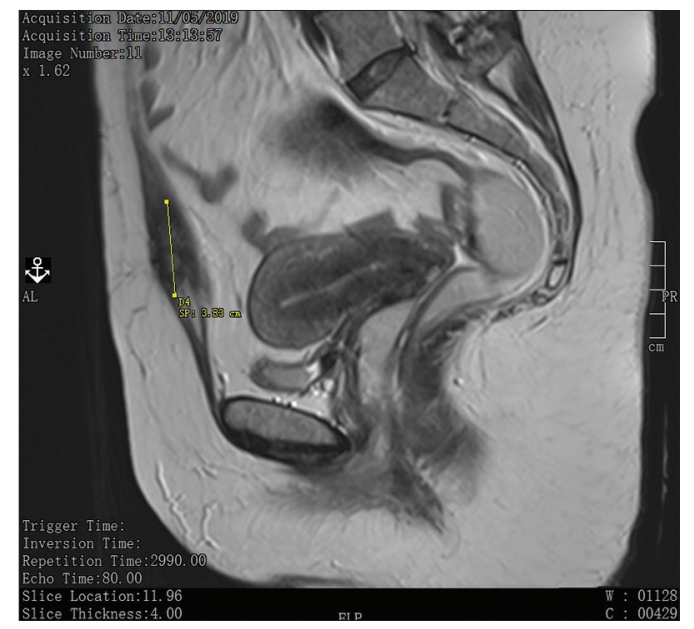

Figure 5: Abdominal magnetic resonance imaging in sagital plane revealing abdominal wall nodule

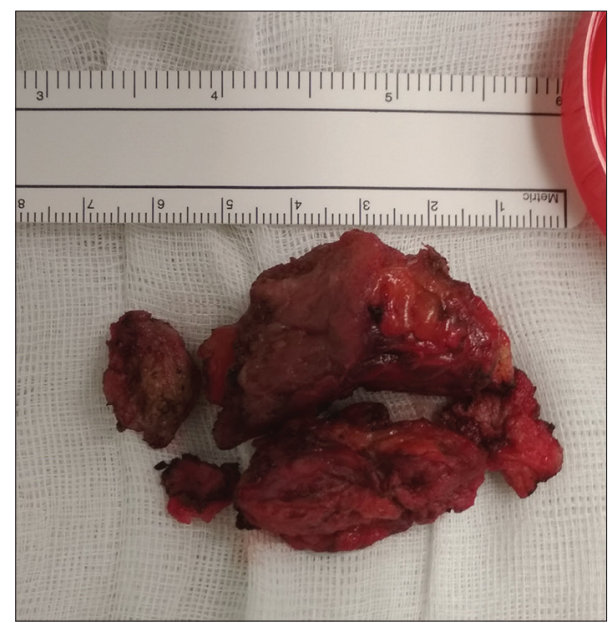

Figure 7: Hard median nodule with $5 \mathrm{~cm}$ length removed from the rectus abdominis muscles and fascia (ex vivo picture)

was enlarged, and there was a $3 \mathrm{~cm}$ cyst in the left ovary. The abdominal wall cyst was removed, and ovarian cystectomy,

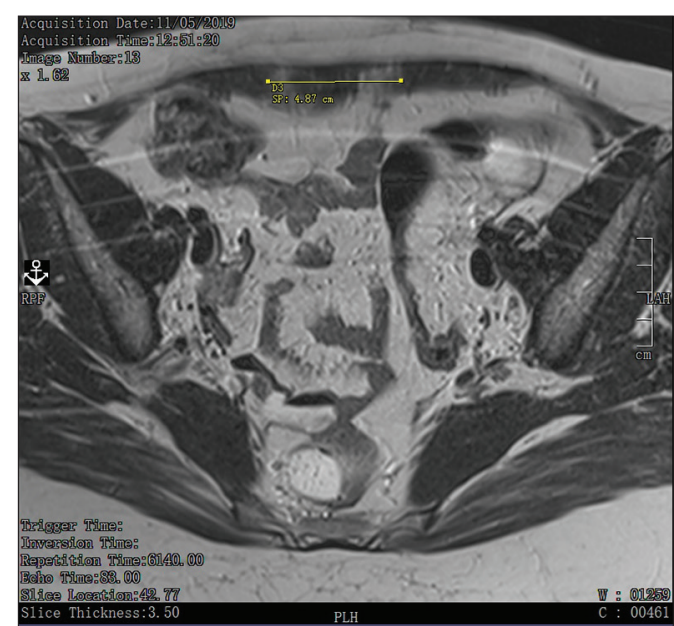

Figure 4: Abdominal magnetic resonance imaging in the axial plane revealing abdominal wall nodule

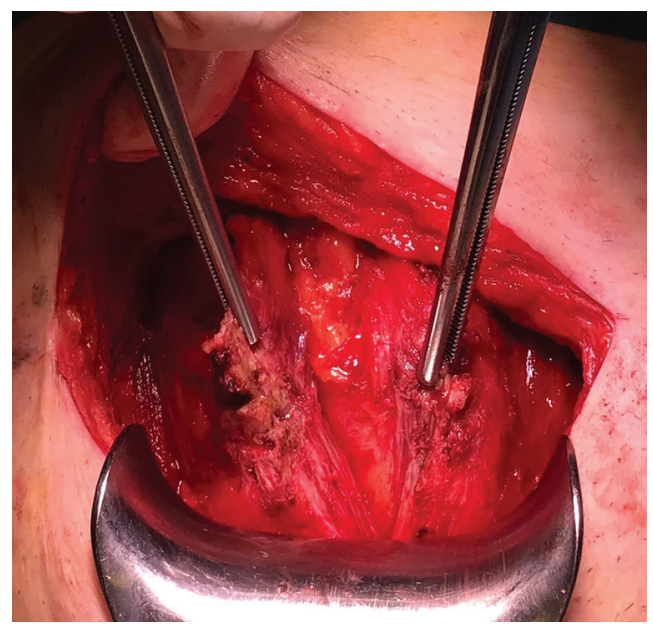

Figure 6: Hard median nodule involving both rectus abdominis muscles and fascia (in vivo picture)

left salpingectomy, and contralateral tubal patency test were performed. The ovarian cyst had a dark brown thick liquid inside. Despite the adhesions, the right adnexa was normal and the right tube was patent.

\section{What IS the Diagnosis?}

\section{Declaration of patient consent}

The authors certify that they have obtained all appropriate patient consent forms. In the form the patient has given her consent for her images and other clinical information to be reported in the journal. The patient understands that her name and initials will not be published and due efforts will be made to conceal identity, but anonymity cannot be guaranteed.

\section{Financial support and sponsorship} Nil.

\section{Conflicts of interest}

There are no conflicts of interest. 